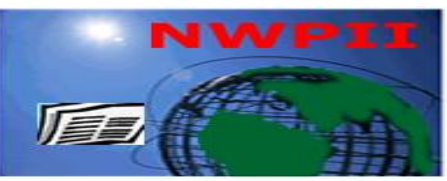

American Journal of Biomedical Sciences

ISSN: 1937-9080

nwpii.com/ajbms

\title{
Dengue Virus Infection among Voluntary Blood Donors in Osogbo, Southwestern Nigeria
}

\author{
Muhibi M A ${ }^{1,2^{*}}$, Adeleke M A ${ }^{3}$, Shittu B T ${ }^{1}$, Jeremiah Z $\mathrm{A}^{4}$ \\ ${ }^{1}$ Haematology and Blood Transfusion Department, Ladoke Akintola University of Technology Teaching Hospital, \\ Osogbo, Osun State, Nigeria. \\ ${ }^{2}$ Medical Laboratory Science Department, Achievers University, Owo, Ondo State, Nigeria. \\ ${ }^{3}$ Public Health Entomology and Parasitology Unit, Department of Biological Science, Osun State University, Osogbo, \\ Osun State, Nigeria. \\ ${ }^{4}$ Medical Laboratory Science Department, Niger Delta University, Wilberforce Island, Bayelsa State, Nigeria. \\ "Corresponding Author \\ Muhibi M A \\ Haematology and Blood Transfusion Department \\ Ladoke Akintola University of Technology Teaching Hospital \\ Osogbo, Osun State \\ Nigeria \\ Email: muhibudeen@yahoo.com
}

Received: 28 April 2017; | Revised: 21 July 2017; | Accepted: 30 July 2017

\begin{abstract}
Dengue virus is one of the causative agents of viral haemorrhagic fever, which is transmitted primarily through Aedes mosquitoes. Transmission of the virus through non-vector sources had been proven, although, it is the most common arthropod-borne viral infection in human. This study was carried out to determine the prevalence of Dengue Virus amongst voluntary blood donors in Osogbo, southwest Nigeria. Ninety one voluntary non-remunerated donors that satisfied donor suitability criteria in Nigeria; having been considered fit based on physical assessment, responses provided to Blood Donors' questionnaire, and tested negative by both rapid diagnostic and ELISA techniques to HIV $1 \& 2, \mathrm{HBV}, \mathrm{HCV}$ and syphilis were screened for antiDengue IgM antibody using Enzyme Linked Immuno-Sorbent Assay (ELISA). It was observed that most of the donors (56.04\%) fall within age group 28-37 years, while none of the participant was older than 47 . In terms of gender distribution, men $(86.81 \%)$ were in the majority. Marital profile showed that most of the participants were unmarried (72.53\%); while literates account for $58.24 \%$. The seroprevalence of IgM antibodies showed that only two $(2.2 \%)$ participants were positive for Dengue virus. Result showed that there is low prevalence of Dengue virus among voluntary blood donors in Osogbo. Monitoring the trends in prevalence of transmissible infectious agents in blood donors will provide a mechanism to evaluate the safety of the blood supply. It is hereby recommended that surveillance be sustained on all emerging and reemerging infectious diseases that have potentials of being transmitted through blood transfusion, dengue virus inclusive.
\end{abstract}


Keywords: Dengue, transfusion transmissible infection, haemorrhagic fever, blood safety, ELISA.

\section{Introduction}

Dengue virus (DENV) is one of the causative agents of viral haemorrhagic fever ${ }^{[1]}$. The virus circulating in the blood of viraemic human is ingested by female mosquitoes (Aedes) during feeding. The virus then infects the mosquito midgut and subsequently spreads systemically over a period of $8-12$ days. After this extrinsic incubation period, the virus can be transmitted to other humans during subsequent probing or feeding ${ }^{[2]}$.

However, incidences have been reported when dengue viruses were transmitted without the involvement of the Aedes vector. Cases of percutaneous transmission via needle stick injuries, mucocutaneous transmission through a blood splash to the face, vertical transmission and transmission via bone marrow transplant were reported ${ }^{[3]}$.

Transmission through mucocutaneous exposure was previously incriminated as the source of DENV infection in a health worker in the United State ${ }^{[4]}$. Recent report had shown that exposure during a laboratory-based mosquito infection and transmission experiments resulted in an acute DENV infection of the laboratory scientist ${ }^{[5]}$. In this instance, the experiments involved exposing colony-reared uninfected mosquitoes to an artificial blood meal containing DENV-2 via a membrane feeding apparatus. The high sequence homology and phylogenetic relatedness between the virus obtained from the patient and the virus used during the vector competence experiments confirms that they were identical strains and strongly suggests that the patient acquired the infection during the course of this procedure ${ }^{[5]}$.

Infection with Dengue virus causes classic dengue fever (DF), dengue hemorrhagic fever (DHF) or dengue shock syndrome (DSS), but asymptomatic infection could also occur. After an incubation period of 4--10 days, infection by any of the virus serotypes can produce a wide spectrum of illness, while some infections manifest no symptom [6]

Although dengue has been documented to be in Africa continent for about 90 years ago in a retrospective serosurvey by Kokernot et al which suggested that dengue in Africa existed as far back as $1926-1927^{[7]}$, Dengue Virus 1(DEN-1), Dengue Virus 2(DEN-2) and Dengue Virus 3(DEN-3) were isolated for the first time in 1960 in Nigeria ${ }^{[8]}$. Subsequently, dengue has been found to occur in Senegal and Burkina Faso (predominantly being transmitted in sylvatic cycles), and possibly in other tropical rainforests in western Africa ${ }^{[9,10,11]}$. The literature revealed that the prevalence of dengue virus varies from one population to another and constitute a source of concern in tropical countries, Nigeria inclusive ${ }^{[12]}$.

The aim of this study was to determine prevalence of Dengue virus among asymptomatic adults who have been found fit as blood donors in Osogbo, Southwest Nigeria.

\section{Materials and Methods}

\subsection{Study Area}

A total of 91 voluntary non-remunerated donors that satisfied donor suitability criteria in Nigeria; having been considered fit based on physical assessment, responses provided to Blood Donors' questionnaire, and tested negative by both rapid diagnostic and ELISA techniques to HIV 1 \& 2, HBV, HCV and syphilis were recruited for this study. Hence, every participant was a consenting individual with no symptom of any febrile illness or haemorrhagic disorder that approached the Blood Bank for voluntary blood donation between January and December, 2015. The participants' ages were between 18 and 65 years, with a minimum body weight of $50 \mathrm{~kg}$ and $\mathrm{PCV}$ of $\geq 37 \%$ for male; and $45 \mathrm{~kg}$ and $\mathrm{PCV}$ of $\geq 35 \%$ for female respectively.

\subsection{Sample processing}

Five milliliters of venous blood was drawn aseptically from each participant by venipuncture into vacuum EDTA tube. The specimens were centrifuged at 1200 revolution per minute (rpm) for 
5 minutes to harvest plasma into a microtube for the

generation Enzyme Immuno-Assay (ELISA) kit produced by DIA.PRO, Italy.

Diluted donor's plasma and neutralizing reagent were added to the microwells before one hour incubation at $37^{\circ} \mathrm{C}$. The controls were treated accordingly while A1 well was reserved for blanking. After washing with microplate washer, a volume of $100 \mu \mathrm{l}$ of horseradish peroxidase conjugated polyclonal antibodies to human IgM (enzyme conjugate) was added to every well before 60 minutes incubation. Final 20 minutes incubation was preceded with addition of chromogen, and the reaction was stopped. During incubation, the specific immunocomplex formed in case of presence of anti-Dengue virus (IgM) in the sample, was captured on the solid phase which generates an optical signal that is proportional to the amount of anti-Dengue virus antibodies present in the sample.

The commercially prepared positive and negative controls were treated alongside the specimens. A cut-off value was determined and results were interpreted as positive and negative according to manufacturer's instructions ${ }^{[13,14]}$.
Dengue Virus IgM antibodies testing with third

\section{Results}

Out of the 91 voluntary blood donors recruited for Dengue virus $\operatorname{IgM}$ screening, 51 $(56.04 \%)$ were in the active age group (28-37 years) accounting for the majority of the participants. None of the participant was older than 47. In terms of gender distribution, men $(86.81 \%)$ were in the majority. Marital profile showed that most of the participants were unmarried (72.53\%); while others were married. Most of the research participants were literate, with 53 (58.24\%) among them having post secondary school qualifications (Table 1). The results of the seroprevalence of IgM antibodies showed that only two (2.2\%) participants were tested positive. The two seropositive individuals were men within the age group of 28-37 years (Figure 1). When subjected to pearson's chi square analysis using statistical package for science students (SPSS) version 20, none of the demographical variables was established to have effect on positivity to antiDengue IgM antibodies (Table 2) as all p values $>$ $0.05)$.

\section{Prevalence of anti-Dengue virus antibodies (IgM)}

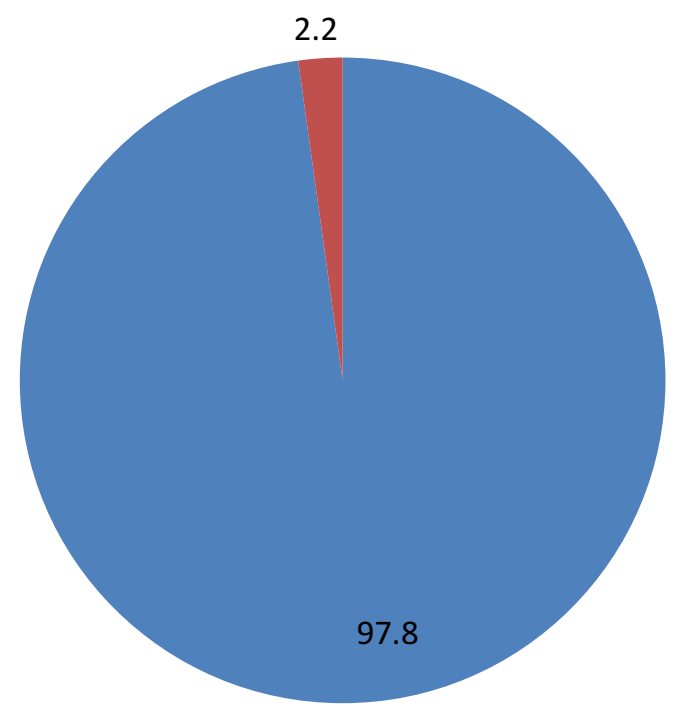

Denge negative

Denge positive

Figure 1: Prevalence of anti-Dengue virus antibodies (Ig M) among voluntary blood donor 
Table 1. Socio-demographic characteristics of voluntary blood donors recruited

\begin{tabular}{|c|c|c|}
\hline Characteristics & Frequency & $\%$ \\
\hline \multicolumn{3}{|l|}{ Age (Year) } \\
\hline $18-27$ & 35 & 38.46 \\
\hline $28-37$ & 51 & 56.04 \\
\hline $38-47$ & 05 & 5.50 \\
\hline \multicolumn{3}{|l|}{ Gender } \\
\hline Male & 79 & 86.81 \\
\hline Female & 12 & 13.19 \\
\hline \multicolumn{3}{|l|}{ Marital status } \\
\hline Married & 25 & 27.47 \\
\hline Single & 66 & 72.53 \\
\hline \multicolumn{3}{|l|}{ Educational level } \\
\hline Illiterate & 04 & 4.40 \\
\hline Primary school & 12 & 13.19 \\
\hline Secondary schoo & 15 & 16.48 \\
\hline Undergraduate/Graduate & 53 & 58.24 \\
\hline Arabic education only & 07 & 7.69 \\
\hline \multicolumn{3}{|l|}{ Occupation } \\
\hline Unemployed & 02 & 2.20 \\
\hline Traders & 04 & 4.40 \\
\hline Professionals/Business men & 31 & 34.06 \\
\hline Students & 48 & 52.75 \\
\hline Civil Servants & 06 & 6.59 \\
\hline
\end{tabular}

Table 2. Effect of socio-demographic characteristics of voluntary blood donors on positivity to anti-Dengue virus antibodies (Ig M)

\begin{tabular}{|c|c|c|}
\hline & p-value & Comment \\
\hline Age & 0.421 & Not significant \\
\hline Gender & 0.448 & Not significant \\
\hline Marital status & 0.319 & Not significant \\
\hline Education & 0.265 & Not significant \\
\hline Occupation & 0.306 & Not significant \\
\hline
\end{tabular}

\section{Discussion}

Prevalence of Dengue virus infection among voluntary non remunerated donors in Osogbo is low $(2.2 \%)$ and the figure may be considered negligible when the $2 \%$ possibility of false positive result is considered in a kit with $98 \%$ specificity ${ }^{[15,16,17]}$. This result agrees with the results of study conducted by Baba et al in 2009 where dengue virus prevalence for Nigeria and Ibadan (a 
southwestern Nigeria city) were $0.67 \%$ and $0.9 \%$ respectively ${ }^{[18]}$. Incidentally, a positive $\operatorname{IgM}$ result on plasma sample suggests the infection occurs in the previous one to two months before sample collection ${ }^{[19]}$. Although, higher prevalence was recently reported in some studies in Nigeria ${ }^{[20,21]}$, the testing method used for these studies predisposes to cross-reactivity to other flavivirus infections or yellow fever vaccination, as IgG screening technique was adopted by most of these researchers who worked on symptomatic patients.

Transmission of dengue virus through blood transfusion becomes a blood safety issue because, possibility of contracting the virus through exposure to blood from non- vector sources was proven ${ }^{[4,5]}$. More so, the Aedes vector usually transmits this infection through blood meal too ${ }^{[2]}$. However, it was postulated that family blood donation and remunerated blood donation, mostly found in developing countries is statistically associated with higher prevalence of infectious diseases ${ }^{[22,23]}$. Hence, this low prevalence among voluntary blood donors confirms the concept that this group constitutes the low-risk group in terms of infection transmission.

\section{Conclusion}

Monitoring the trends in prevalence of transmissible infectious agents in blood donors will provide a mechanism to evaluate the safety of the blood supply. Increase in incidence and prevalence rate of an infectious disease agent is not uncommon because of interplay of factors like changes in population risks; the introduction of new screening technique, migration and occurrence of epidemics.

It is hereby recommended that surveillance be sustained on all emerging and re-emerging infectious diseases that have potentials of being transmitted through blood transfusion, dengue virus inclusive. Recruitment and patronage of voluntary blood donors remains the safest approach to blood transfusion practice, and stakeholders in Nigeria and other Africa countries should embrace the culture religiously.

The limitation of the study includes nonavailability of support to fund procurement of reagents in quantity beyond 91 samples, having dedicated 5 wells to run controls in a 96 well ELISA plate. This is due to ongoing recession in
Nigeria primarily, and non-availability of data to be used as template for sample size determination in terms of prevalence of dengue virus among blood donors in Nigeria.

\section{Conflict of interest}

The author declares that there is no conflict of interest.

\section{References}

1. Halstead SB. Pathogenesis of dengue: challenges to molecular biology.Science 1988; 239(4839): 476-481 [PMID: 3277268]

2. de la CSB, Kouri G, Guzman MG. Race: a risk factor for dengue hemorrhagic fever.Arch Virol 2007; 152(3): 533-542 [PMID: 17106622 DOI: 10.1007/s00705-006-0869-x]

3. Chen L, Wilson M. Non-Vector transmission of dengue and other mosquito-borne flaviviruses. Dengue Bulletin 2005;29:18-31.

4. Chen LH, Wilson ME. Transmission of dengue virus without a mosquito vector: nosocomial mucocutaneous transmission and other routes of transmission. Clin Infect Dis 2004; 39(6): e5660 [PMID: 15472803 DOI: 10.1086/423807]

5. Britton $S$, van den Hurk AF, Simmons RJ, Pyke AT, Northill JA, McCarthy J, McCormack J. Laboratory-acquired dengue virus infection--a case report. PLoS Negl Trop Dis 2011; 5(11): e1324 [PMID: 22140587 PMCID: PMC3226549 DOI: 10.1371/journal.pntd.0001324]

6. Ngo NT, Cao XT, Kneen R, Wills B, Nguyen VM, Nguyen TQ, Chu VT, Nguyen TT, Simpson JA, Solomon T, White NJ, Farrar J. Acute management of dengue shock syndrome: a randomized double-blind comparison of 4 intravenous fluid regimens in the first hour. Clin Infect Dis 2001; 32(2): 204-213 [PMID: 11170909 DOI: $10.1086 / 318479]$

7. Kokernot RH, Smithburn KC, Weinbren MP Neutralising antibodies to arthropodborne viruses in human and animals in the Union of South Africa. Journal of Immunology. 1956, 77:313-322. 
8. Carey DE, Causey OR, Reddy S, Cooke AR. Dengue viruses from febrile patients in Nigeria, 1964-68. Lancet 1971; 1(7690): 105-106 [PMID: 4099602]

9. Collenberg E, Ouedraogo T, Ganame J, Fickenscher H, Kynast-Wolf $\mathrm{G}$, Becher $\mathrm{H}$, Kouyate B, Krausslich HG, Sangare L, Tebit DM. Seroprevalence of six different viruses among pregnant women and blood donors in rural and urban Burkina Faso: A comparative analysis. J Med Virol 2006; 78(5): 683-692 [PMID: 16555290 DOI: 10.1002/jmv.20593]

10. Kuniholm MH, Wolfe ND, Huang CY, MpoudiNgole E, Tamoufe U, LeBreton M. Seroprevalence and distribution of Flaviviridae, Togaviridae and Bunyaviridae arboviral infections in rural Cameroonian adults. $\boldsymbol{A m} \boldsymbol{J}$ Trop Med Hyg. 2006; 74:1078- 1083.

11. Amarasinghe A, Beatty ME, Wichmann O, Kuritsky JN, Margolis HS, Letson GW. Comparison of epidemiological field site surveillance of dengue. In: Abstracts of the 5th TEPHINET Southeast Asia and Western Pacific Bi-Regional Scientific Conference,Seoul, South Korea, Nov 2-6, 2009.

12. Anderson KB, Chunsuttiwat S, Nisalak A, Mammen MP, Libraty DH, et al(2007 ). Burden of symptomatic dengue infection in children at primary school in Thailand: a prospective study. Lancet; 369:1452-1459. DOI: 10.1016/S01406736(07)60671-0

13. Lima MDRQ, Nogueira RMR, Bispo de Filippis AM, dos Santos FB. Comparison of two generations of the Panbio dengue NS1 capture enzyme-linked immunosorbent assay. Clin.Vaccine Immunol. 2011; 18:1031-1033. DOI: 10.1128/CVI.00024-11

14. Stuart D. Blacksell, Richard G. Jarman, Robert V. Gibbons, Ampai Tanganuchitcharnchai, Mammen P. Mammen, Jr., Ananda Nisalak, Siripen Kalayanarooj, Mark S. Bailey, Ranjan Premaratna, H. Janaka de Silva, Nicholas P. J. Day, and David G. Lalloo (2012). Comparison of Seven Commercial Antigen and Antibody Enzyme-Linked Immunosorbent Assays for Detection of Acute Dengue Infection. Clin
Vaccine Immunol.; 19(5): 804-810. DOI: 10.1128/CVI.05717-11

15. Ageep A K, Malik A A, Elkarsani SM S. Clinical presentations and laboratory findings in suspected cases of dengue virus. Saudi Med J. 2006; 27 (11): 1711-1713.

16. Hapugoda M D, Batra G, Abeyewickreme W, Swaminathan S, Khanna N. Single antigen detects both immunoglobulin $\mathrm{M}$ (IgM) and $\operatorname{IgG}$ antibodies elicited by all four dengue virus serotypes. Clin Vaccine Immunol. 2007; 14(11): 1505-1514. DOI: 10.1128/CVI.0014507

17. Kumarasamy V, Chua S K, Hassan Z, Wahab A H, Chem Y K, Mohamad M, Chua K B. Evaluating the sensitivity of a commercial dengue NS1 antigen-capture ELISA for early diagnosis of acute dengue virus infection. Singapore Med J. 2007; 4897): 669-673.

18. Baba M M, Marie-Francois Saron, Vorndam A V, Adeniji J A, Diop O, Olaleye D.Dengue Virus Infection in Patients Suspected of Malaria/Typhoid in Nigeria. Journal of American Science. 2009; 5(5): 129-134.

19. Regional guidelines on dengue 1 DHF prevention and control.World Health Organisation. 2001; 1-5.

20. Adedayo F, Nioma I, Olanrewaju M B, Adeyinka A, Ebele A. Serological evidence of Recent dengue virus infection among febrile children in a semi-arid zone. Am $\boldsymbol{J}$ Infect Dis. 2013; 9(1): 7-10.

21. Olufunmilayo G Oyero, James A Ayukekbong. High dengue NS1 antigenemia in febrile patients in Ibadan, Nigeria. Virus Research. 2014; 191: 59-61. DOI: 10.1016/j.virusres.2014.07.023

22. Batina, A., Kabemba, S. and Malengela, R. (2007). Infectious markers among blood donors in Democratic Republic of Congo (DRC). Revue Médicale de Bruxelles 28(3): 145-149.

23. Tagny, C.T., Owusu-ofori, S., Mbanya, D. and Deneys, V. (2010). The blood donor in subSaharan Africa: a review. Transf Med. 20: 1-10. 